\title{
A Long Pulse Discharge Excited ArF Laser
}

\author{
L. Feenstra, H. M. J. Bastiaens, P. J. M. Peters, and W. J. Witteman
}

\begin{abstract}
An X-ray preionised, discharge excited ArF excimer laser, $\lambda=193 \mathbf{n m}$, has been studied in the long pulse regime. The laser performance is found to be primarily dependent on the discharge stability, and therefore, on the gas composition, preionization timing and the pumping power. Using $\mathrm{X}$-ray preionization and prepulse-mainpulse excitation, laser pulselengths of up to 120-ns full-width at half-maximum at $4 \mathrm{~mJ} / \ell$ are obtained by decreasing the partial pressures of the active ingredients, $F_{2}$ and Ar, and using Ne as a buffergas. This is almost six times as long as usual for discharge excited ArF lasers.
\end{abstract}

Index Terms-Excimer lasers, gas discharges, laser excitation, pulsed lasers, ultraviolet generation.

\section{INTRODUCTION}

$\mathbf{I}$ $\mathrm{N}$ THE PAST few years, much research has been performed on pulse lengthening of discharge pumped excimer lasers [1]-[4]. Long laser pulses increase the control of beam quality, both spatially and spectrally. Long pulses also relieve stress on the optics, caused by compaction and colorcenter formation because the same pulse energy is obtained at a lower intensity. Therefore, longer pulses of these short-wavelength lasers are of interest for use in nano-lithography, in eye surgery and in cutting and drilling. Long laser pulses also facilitate the transport of optical signals through fibers. It has also been shown that long excimer laser pulses are very interesting for the generation of long X-ray pulses for the in vivo study of bacteria [5]. Furthermore, long pulse operation lowers stress on the electrical components of the setup.

In halogen containing laser gas mixtures, the discharge homogeneity deteriorates rapidly due to discharge filamentation and arc-formation as a consequence of dissociative electron attachment and the process of halogen depletion [6]-[8]. Therefore, long pulse discharge excited lasers usually operate with mixtures containing only small quantities of the active gases in several atmospheres of a buffer gas [9]-[11].

Optical pulselengths of over $1 \mu \mathrm{s}$ have been reported for $\mathrm{XeCl}$ [1]. Nevertheless, pulse lengthening in fluorine containing laser gas mixtures is more difficult. For $\mathrm{KrF}$ and $\mathrm{F}_{2}$ the longest reported laser pulses are $170 \mathrm{~ns}$ [2] and $70 \mathrm{~ns}$ [4], respectively, while the reported pulselengths of discharge pumped ArF lasers do not exceed 20 ns.

Using X-ray preionization and a magnetically switched prepulse-mainpulse circuit, with a minimum self inductance of the peaking circuit, in accordance with previous successful developments on excimer lasers [4], [9], [12], we were able

Manuscript received March 26, 1999; revised June 14, 1999. This work was supported by the Netherlands Technology Foundation STW.

The authors are with the University of Twente, 7500 AE Enschede, The Netherlands.

Publisher Item Identifier S 1077-260X(99)09898-6.

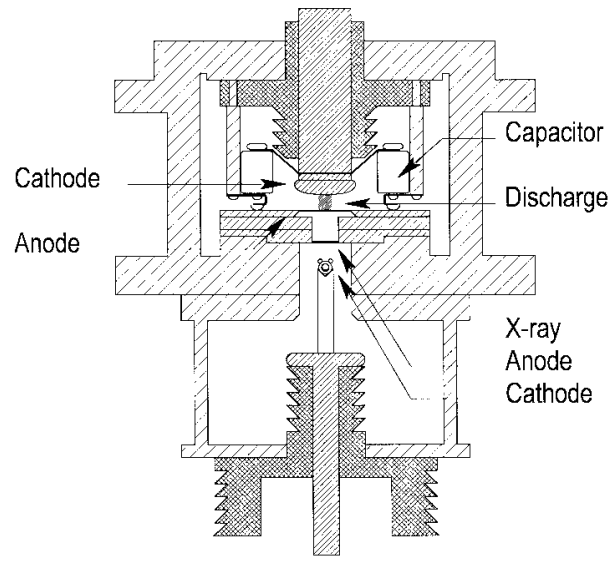

Fig. 1. The laserhead and the X-Ray source. The discharge is preionised through the anode.

to operate the ArF laser in the long-pulse regime, generating laser pulselengths up to $120 \mathrm{~ns}$.

In this paper, we present some results of a parametric study on the pulselength and the output energy of the laser. The results show that there is a clear tradeoff between the laser gain and the discharge stability, and therefore between the output energy and the pulselength.

\section{EXPERIMENTAL SETUP}

A cross-sectional view of the experimental setup is shown in Fig. 1. The laserhead is a rectangular stainless steel vessel, fitted at opposite sides with uncoated $\mathrm{MgF}_{2}$ windows. The resonator is formed by a high reflectivity mirror with a 6-m concave radius and a plane $90 \%$ reflection outcoupler. The laser mirrors are placed outside the laser vessel, to keep them from contact with the fluorine containing gas mixture. The brass laser cathode is of the uniform field type [13]. The grounded anode is flat and is made of nickel plated aluminum. The discharge volume is approximately $60 \times 0.7 \times 1.2 \mathrm{~cm}^{3}$ $(l \times w \times h)$.

The gas mixture is preionised through the laser anode by a short pulse, high intensity X-ray source, using a coronaplasma cathode and a tungsten anode [14], [15]. The $50 \mathrm{~ns}$ full-width at half-maximum (FWHM) X-ray pulse is capable of generating an electron density of up to $8 \times 10^{7} \mathrm{~cm}^{-3} \mathrm{bar}^{-1}$ in pure helium and up to $1.5 \times 10^{9} \mathrm{~cm}^{-3} \mathrm{bar}^{-1}$ in pure argon.

The laser is excited by a ferrite-switched prepulse-mainpulse circuit, operated in the resonant overshoot mode, see Fig. 2 [10], [16]. The capacitance of the pulse forming network $(\mathrm{PFN}), C_{\mathrm{PFN}}$ is $427.2 \mathrm{nF}$. The peaking capacitor $C_{P}$ consists of ten capacitors of $460 \mathrm{pF}$ (at $0 \mathrm{~V}$ ) each. Once the PFN is charged, a fast, high voltage prepulse of opposite polarity 


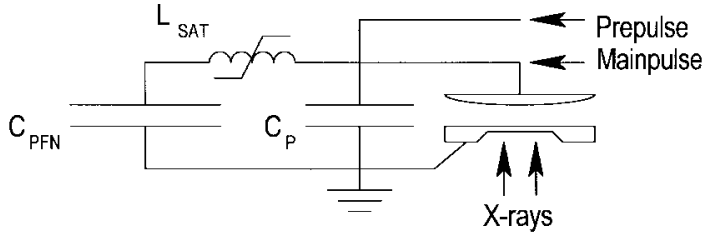

Fig. 2. The excitation circuit, operated in the resonant overshoot mode. $C_{\mathrm{PFN}}=427.2 \mathrm{nF}, C_{\mathrm{P}}=3.6 \mathrm{nF}, L_{\mathrm{SAT}}$ Saturable inductor, acting as switch.

to the mainpulse switches the saturable inductor from a high inductive state to a low inductive state. This causes a current to flow from the PFN to the peaking capacitors, thus generating a high voltage overshoot, which causes the breakdown of the gas. The current from the PFN subsequently sustains the discharge.

The peaking capacitors are placed inside the laser vessel to minimize the self inductance of the setup in the first stages of the discharge, see Fig. 1. The low self inductance is especially important because a short current risetime causes a more homogeneous cathode sheet ignition and a denser cathode hot spot structure than a circuit with a slower current rise. Thus the homogeneity of the bulk of the discharge is increased which allows a longer discharge stability and hence a longer laser pulse [17]-[19]. No lasing could be observed under the same experimental conditions but with the peaking capacitors mounted outside the laser vessel.

The standard gas mixture of the experiments consists of $1.0 \mathrm{mbar}_{2}$, 19.1 mbar $\mathrm{He}, 50.0$ mbar Ar, the buffer gas $\mathrm{Ne}$ is added to a total gas pressure of 5 bar, thus $\mathrm{F}_{2} / \mathrm{He} / \mathrm{Ar} / \mathrm{Ne}=$ $0.02 / 0.38 / 1.00 / 98.60$. The He in the gas mixture is a consequence of the fluorine being applied in the form of a mixture of $4.95 \% \mathrm{~F}_{2}$ in He. Each gas mixture is freshly made before the experiment and it is thoroughly mixed by the flow of a liquid nitrogen gas-purifier (ca. $15 \ell / \mathrm{min}$ ) in approximately $20 \mathrm{~min}$. The gas mixture is constantly flowed through the purifier during the experiments.

The laser is operated at a PFN-voltage of $5.3 \mathrm{kV}$, which is slightly higher than the optimum value of twice the steady state voltage, to increase the pumping power. The prepulse charging voltage is kept at $20 \mathrm{kV}$ throughout the experiments.

The current and voltage signals are measured with resistive probes, the optical signal is measured with an UV sensitive photodiode and a 193-nm filter, placed behind the high reflectivity mirror which has a transmittance of approximately $0.5 \%$. Fig. 3 shows typical waveforms of the X-ray voltage, the discharge voltage, the discharge current and the optical signal.

Unless stated otherwise, the experimental conditions are kept the same throughout the experiment.

\section{EXPERIMENTAL RESULTS AND DISCUSSION}

\section{A. Dependence on Preionization Timing}

One of the most important parameters for obtaining a good discharge quality is the discharge start, governed by the multiplication of the preionization electron density,

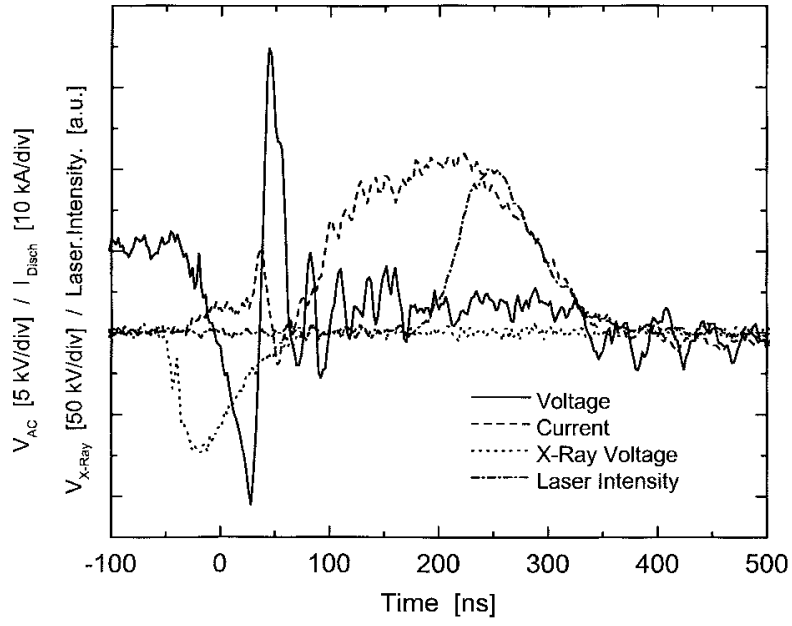

Fig. 3. Typical waveforms of the laser. Gas mixture: 5 bar, $\mathrm{F}_{2} / \mathrm{Ar} / \mathrm{He} /$ $\mathrm{Ne}=0.75 / 50.0 / 15.2 /$ rest. $V_{\mathrm{PFN}}=5.3 \mathrm{kV}$.

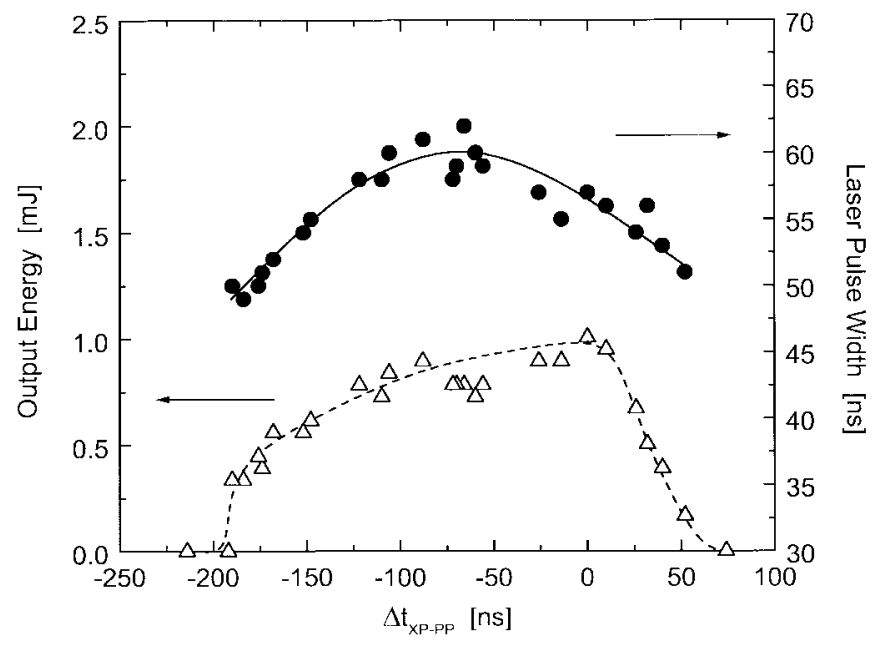

Fig. 4. Laser pulselength (FWHM) and output energy versus the preionization delay time $\Delta t_{\mathrm{XP}-\mathrm{PP}}$. Gas mixture: 5 bar, $\mathrm{F}_{2} / \mathrm{Ar} / \mathrm{He} /$ $\mathrm{Ne}=1.0 / 50.0 / 19.1 /$ rest.

$N_{e} \approx 10^{8} \mathrm{~cm}^{-3}$, to that of a full-fledged discharge, $N_{e} \approx 10^{15} \mathrm{~cm}^{-3}$ [20]. We studied the effect of small preionization timing variations on the optical performance.

An early preionization gives much time to the fluorine for attachment of the preionization electrons, causing small scale inhomogeneities in the electron density. Applying the preionization pulse late means that there is less time for electron multiplication from the preionization electron density to the discharge level. In both cases, an inhomogeneous discharge can occur [21].

In Fig. 4, the pulse width and the optical output energy are shown as a function of the time delay of the onset of the X-ray pulse relative to the start of the prepulse. It is clear that the preionization timing has a strong influence on the laser performance. The optimum pulselength is found at a preionization timing of $\Delta t_{\mathrm{XP}-\mathrm{PP}} \approx-75 \mathrm{~ns}$. This means that the maximum X-ray pulse intensity occurs before the prepulse start. The optimum output energy, however, is found at a shorter preionization delay of $\Delta t_{\mathrm{XP}-\mathrm{PP}} \approx 0 \mathrm{~ns}$, when the start of the X-ray pulse and that of the prepulse 


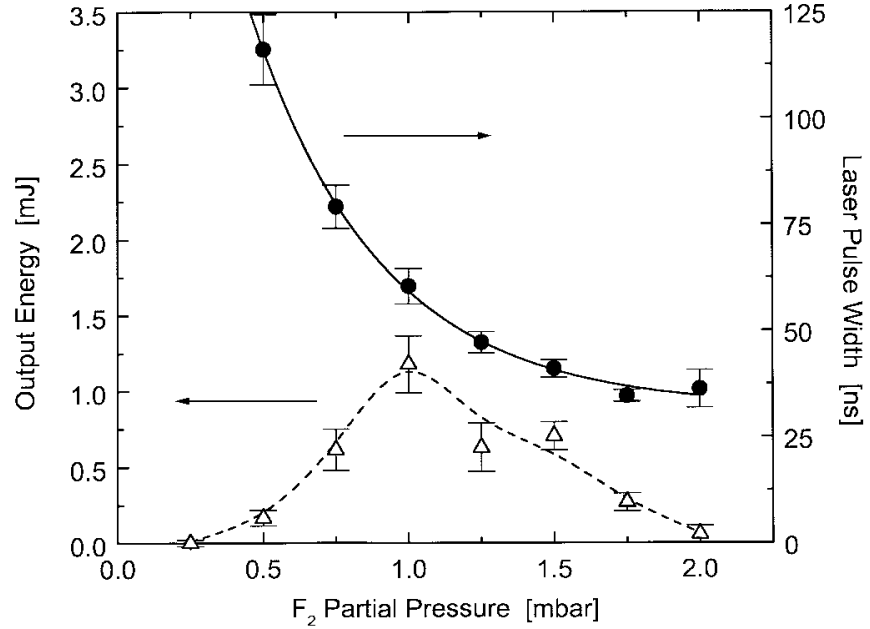

Fig. 5. Laser pulselength (FWHM) and output energy versus $\mathrm{F}_{2}$ partial pressure. Gas mixture: 5 bar, $\mathrm{F}_{2} / \mathrm{Ar} / \mathrm{He} / \mathrm{Ne}=X / 50.0 / 19.1 X /$ rest.

coincide. This difference is caused by a difference in the electron density distribution in the discharge volume. This is due to the diffusion of preionization electrons out of the centre of the preionised region at longer preionization delays, as well as the decrease in the electron attachment by $\mathrm{F}_{2}$ molecules at an increased electrical field strength [22]. The combination of these effects results in a wider discharge with long preionization delays [23]. This causes a lower current density, which in turn results in a lower gain and a lower output energy.

During the experiments the preionization is consistently applied approximately $20 \mathrm{~ns}$ before the onset of the prepulse.

\section{B. Gas Composition}

1) Optical Performance Versus $F_{2}$ Concentration: The discharge stability of excimer lasers is strongly influenced by the concentration of the halogen donor in the gas mixture [1], [4]. Therefore the sensitivity of the laser performance to the fluorine content is studied by varying the partial pressure of the fluorine in the gas mixture.

In Fig. 5, the pulsewidth (FWHM) and the output energy of the laser pulse are shown as a function of the fluorine partial pressure. The data points are the averages of series of shots with a fresh gas mixture. The error bars denote the standard deviation of the results of each series.

The pulselength is seen to increase drastically with lower fluorine pressure, from approximately $35 \mathrm{~ns}$ to $116 \mathrm{~ns}$ when the fluorine pressure is decreased from $2.0 \mathrm{mbar}$ to $0.5 \mathrm{mbar}$ $\mathrm{F}_{2}$. The specific energy of the laser pulse is low at the longest pulses, $4 \mathrm{~mJ} / \ell$, which is probably caused by a low gain due to the low amount of fluorine, as well as the nonoptimized construction of the main circuit of the laser. The optimum output energy of $25 \mathrm{~mJ} / \ell$ is obtained with $1.0 \mathrm{mbar}^{\mathrm{F}} \mathrm{F}_{2}$, in a pulse of approximately $61 \mathrm{~ns}$.

Fig. 6 shows the discharge current and the laser intensity for a number of different fluorine pressures. It can be seen that the laser pulse occurs earlier in the discharge with increasing fluorine pressure. When the fluorine pressure increases over

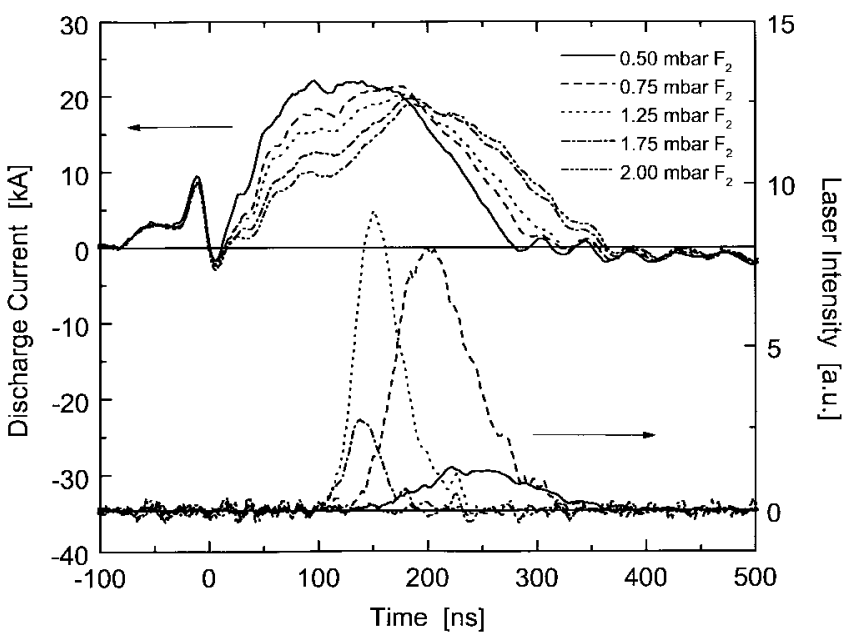

Fig. 6. Typical current and photodiode signals with different $\mathrm{F}_{2}$ partial pressures. Gas mixture: 5 bar, $\mathrm{F}_{2} / \mathrm{Ar} / \mathrm{He} / \mathrm{Ne}=X / 50.0 / 19.1 X /$ rest.

1.25 mbar, the starting point of the laser pulse remains the same, but the pulselength and amplitude rapidly decrease.

The earlier start of the laser pulse with increasing $\mathrm{F}_{2}$ pressures is due to an increased gain, caused by a better efficiency in the reaction kinetics for the formation of the $\mathrm{ArF}^{*}$ molecule. However, the discharge gets increasingly unstable with more fluorine. The impedance collapse of the discharge, due to the breakdown of the discharge into an arcing state can be found from the sudden increase in the current in Fig. 6. With 1.75 mbar $F_{2}$ in the gas mixture the discharge collapse coincides with the build-up of the laser pulse, which therefore is terminated almost immediately.

Additional proof of the deterioration of the discharge quality with an increasing $F_{2}$ concentration is found in the current signals in Fig. 6. When the amount of fluorine in the gas mixture increases, the preionization electron density is decreased faster and the initial impedance of the discharge increases, due to the high electron attachment of $F_{2}$ [12], [22]. Hence, the discharges are more difficult to start, indicated by a slower rising of the current. Further, any small instability will grow more rapidly into streamers and arcs with more fluorine in the gas mixture, due to the halogen depletion mechanism [6], [7]. The time at which the current jump occurs, caused by arcing of the discharge, indeed decreases with increasing fluorine content.

Other loss factors which increase with an increased $\mathrm{F}_{2}$ concentration, are the absorption of the 193-nm radiation by $\mathrm{F}^{-}$and $\mathrm{F}_{2}$, as well as increased quenching of the $\mathrm{ArF}^{*}$ molecule by $\mathrm{F}_{2}$ molecules [24], [25], [26].

Possibly even longer pulses can be obtained from an $\mathrm{ArF}$ laser, when the fluorine pressure is lowered below $0.50 \mathrm{mbar}$ $\mathrm{F}_{2}$, because the pulsewidth and the optical stability time, defined as the time from the start of the discharge to the end of the laser signal, increase faster than the start-up time of the laser pulse with decreasing fluorine partial pressure. However, the power deposition in the discharge must then be increased significantly to overcome the decrease in the gain, caused by the lower $\mathrm{F}_{2}$ concentration. In spite of the low fluorine concentrations we observed no indications of $\mathrm{F}_{2}$ burn up: even 


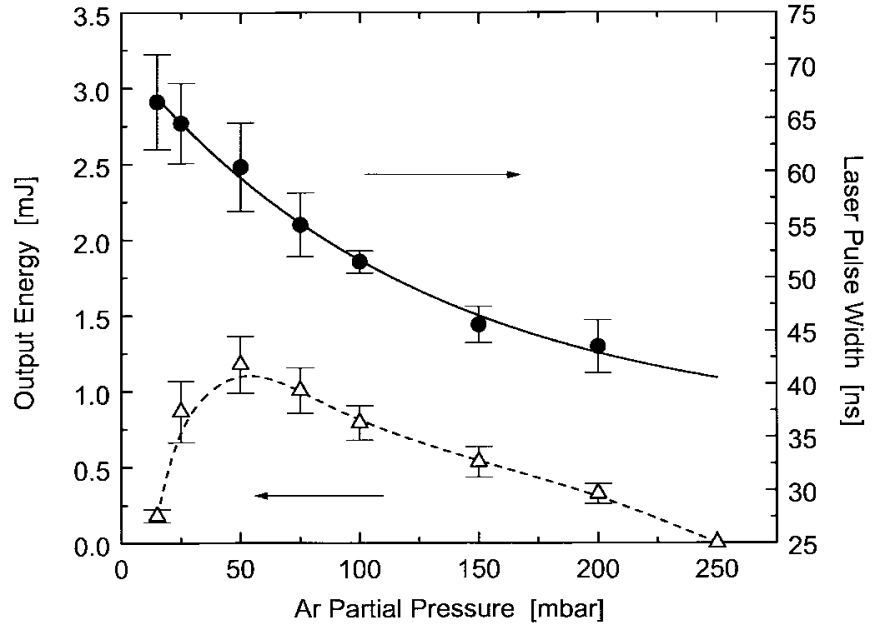

Fig. 7. Laser pulselength (FWHM) and output energy versus Ar partial pressure. Gas mixture: 5 bar, $\mathrm{F}_{2} / \mathrm{Ar} / \mathrm{He} / \mathrm{Ne}=1.0 / X / 19.1 /$ rest.

at a fluorine partial pressure of only $0.5 \mathrm{mbar}$, the laser pulse extends past the end of the current pulse.

2) Optical Performance Versus Ar Concentration: The effect of a variation of the argon partial pressure on the performance of the laser was studied as well. The amount of argon in the gas mixture changes the behavior of the discharge, since more Ar means a higher preionization efficiency, because Ar has a higher cross section for X-rays than $\mathrm{Ne}$ and $\mathrm{F}_{2}$ [12].

From the results, shown in Fig. 7, it can be seen that the laser pulselength decreases with an increasing Ar partial pressure, from $66 \mathrm{~ns}$ at $15 \mathrm{mbar} \mathrm{Ar}$, to approximately $44 \mathrm{~ns}$ at 200 mbar Ar in the gas mixture. The optimum partial pressure for argon with respect to the output energy is found to be 50 mbar, with a pulselength of approximately $61 \mathrm{~ns}$.

We find that the laser pulses occur earlier in the discharge with increasing argon pressure from 15 to 50 mbar. Between 50 and 100 mbar, the pulses start at the same time in the discharge, but the intensity falls increasingly early. At argon pressures over $100 \mathrm{mbar}$, the pulse intensity shows an overall decrease, while the pulse shape remains the same, see Fig. 8.

This behavior indicates an increased gain with increasing Ar pressures, although the inevitable loss mechanisms due to a higher Ar concentration eventually surpass the higher gain. The increased gain is caused by a higher efficiency in the formation of the $\mathrm{ArF}^{*}$ molecule. The gain decrease, which is predominant at an Ar partial pressure higher than $100 \mathrm{mbar}$, is due to a number of processes: the absorption of the $193 \mathrm{~nm}$ radiation by $\mathrm{Ar}_{2}^{*}$ and $\mathrm{Ar}^{* *}$, and an increased quenching of $\mathrm{ArF}^{*}$ by Ar atoms [20], [24]-[27]. A higher Ar concentration causes a higher electron density in the discharge [20], which in turn causes an increased electron quenching of the $\mathrm{ArF}^{*}$ molecules [20], [24]-[26].

From the decreased current rise time in Fig. 8, we can see that better preionization due to the increased amount of Ar in the gas mixture causes a faster breakdown, a better discharge quality and thus a better optical performance. However, increasing the argon in the gas mixture over 50 mbar causes the breakdown voltage of the gas mixture to rise, while the steady state voltage drops. This decreases the discharge stability. The

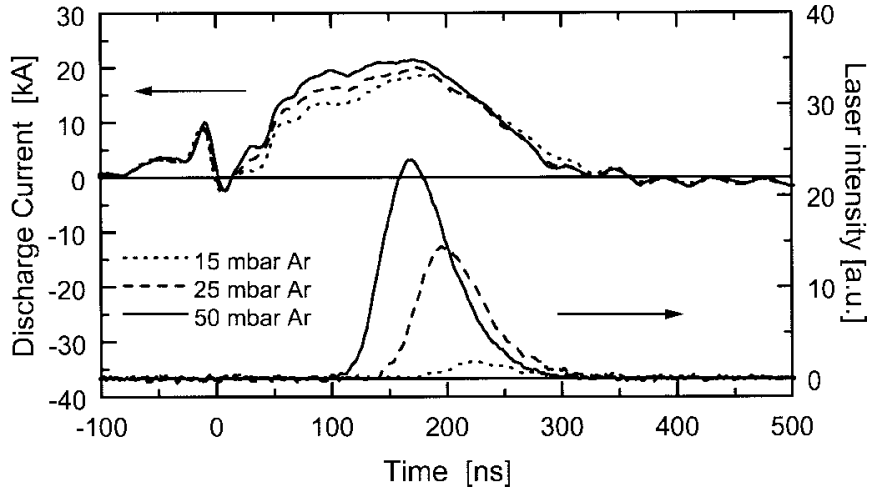

(a)

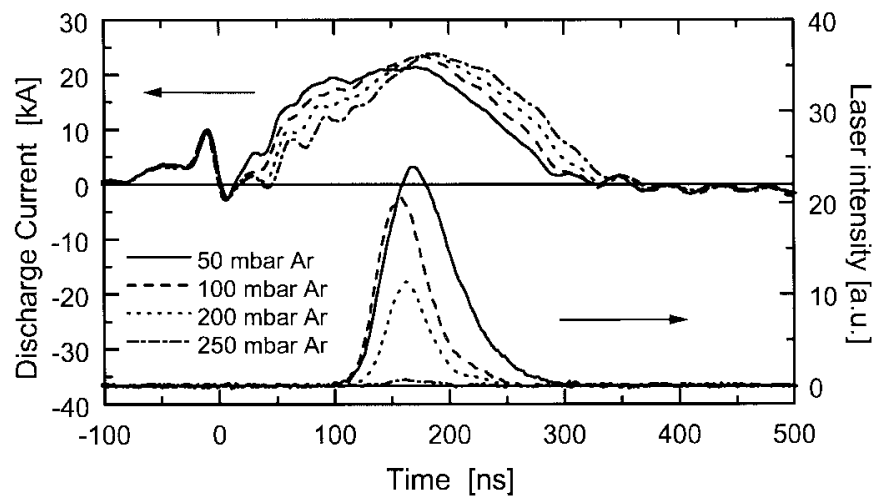

(b)

Fig. 8. Typical current and photodiode signals with different Ar partial pressures, 15-50 mbar (upper panel) and 50-250 mbar (lower panel). Gas mixture: 5 bar, $\mathrm{F}_{2} / \mathrm{Ar} / \mathrm{He} / \mathrm{Ne}=1.0 / X / 19.1 /$ rest.

higher difficulty in starting the discharge can be seen from the current signals in Fig. 8 at Ar pressures over 100 mbar. The increased instability is again indicated by the sudden increase in the current, during the discharge. The discharge instability at higher Ar concentration is probably caused, amongst others, by a lower mean electron energy, which favors the dissociative electron attachment of $F_{2}$ [22], [28], and thus the build-up of instabilities.

3) Optical Performance Versus Total Gas Pressure: The performance of the laser as a function of the total gas pressure was studied by increasing the Ne pressure in a gas mixture containing $1.0 \mathrm{mbar}_{2}, 50.0 \mathrm{mbar}$ Ar and $19.1 \mathrm{mbar}$ He. Each gas mixture was freshly made. All other parameters were kept the same.

From Fig. 9, the width of the laser pulse is seen to decrease steadily when increasing the pressure over $3.5 \mathrm{bar}$, while the output energy peaks at 4.5 bar. The laser pulse is found to start earlier in the discharge when the pressure is increased from 2.5 bar to 4.5 bar. When the pressure is increased over 4.5 bar the laser pulse starts increasingly late. The maximum laser intensity is found to shift to a later time in the discharge when the gas pressure is increased. The maximum intensity is found at the highest current. The laser intensity is reduced uniformly at pressures over 4.5 bar.

This behavior indicates an increasing gain in the laser up to a pressure of $4.5 \mathrm{bar}$, due to an increased efficiency in the formation of the $\mathrm{ArF}^{*}$ molecule due to three-body collisions 


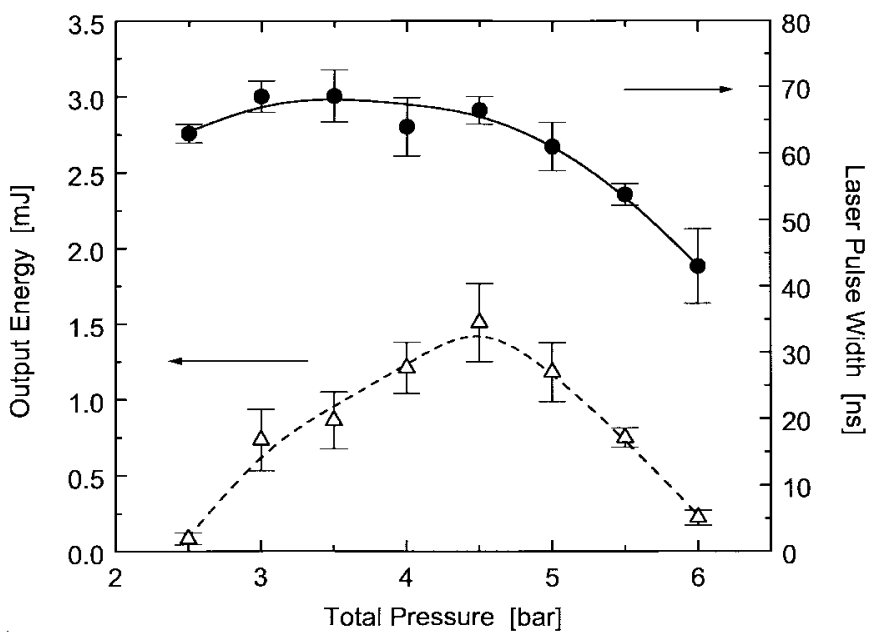

Fig. 9. Laser pulselength (FWHM) and output energy versus total pressure. Gas mixture: $\mathrm{F}_{2} / \mathrm{Ar} / \mathrm{He} / \mathrm{Ne}=1.0 / 50.0 / 19.1 /$ rest.

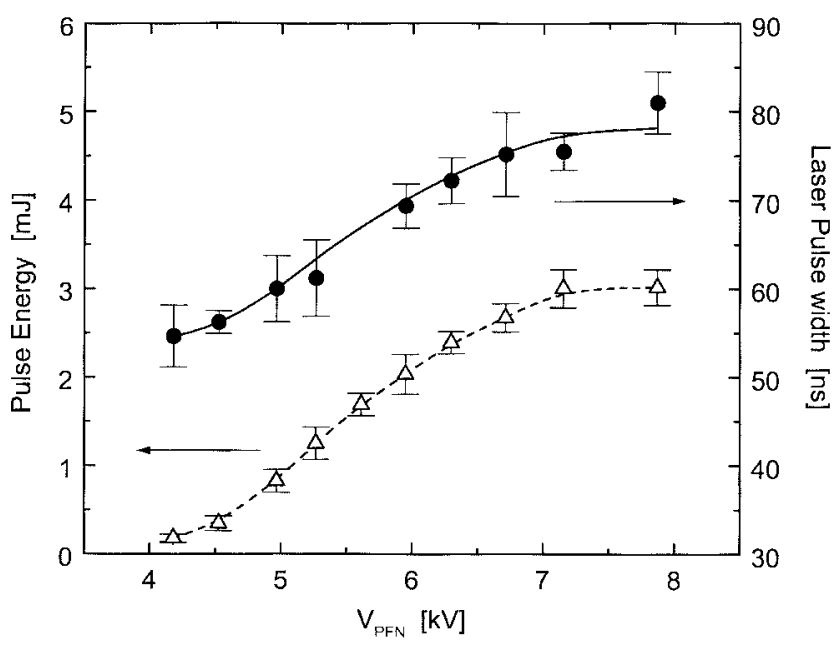

Fig. 10. Laser pulselength (FWHM) and output energy versus PFN voltage $V_{\mathrm{PFN}}$ Gas mixture: 5 bar, $\mathrm{F}_{2} / \mathrm{Ar} / \mathrm{He} / \mathrm{Ne}=1.0 / 50.0 / 19.1 /$ rest.

[20], [24]-[27], [29], [30] and an increased efficiency in the power deposition [31]. The intensity decrease at higher pressures is probably caused by a worse discharge quality due to the higher pressure and an increased quenching of the $\mathrm{ArF}^{*}$ molecules by $\mathrm{Ne}$ [20], [24]-[27].

These effects may be affected by variations in the voltage matching of the system, since the operating voltages have been kept the same throughout the experiments.

\section{Pumping Power}

The dependence of the laser performance on the pumping power is studied by varying the charging voltage of the main capacitor $C_{\mathrm{PFN}}$, while using the standard gas mixture and keeping all other parameters constant.

In Fig. 10, it is shown that the pulselength increases from approximately $55 \mathrm{~ns}$ to $80 \mathrm{~ns}$ FWHM when the PFN-voltage is varied from $4.1 \mathrm{kV}$ to $7.9 \mathrm{kV}$. The growth rate of the pulselength decreases somewhat with higher voltages. The output energy increase, from $0.2 \mathrm{~mJ}(4 \mathrm{~mJ} / \ell)$ to $3.0 \mathrm{~mJ}$ $(60 \mathrm{~mJ} / \ell)$, shows the same behavior. At a PFN voltage of

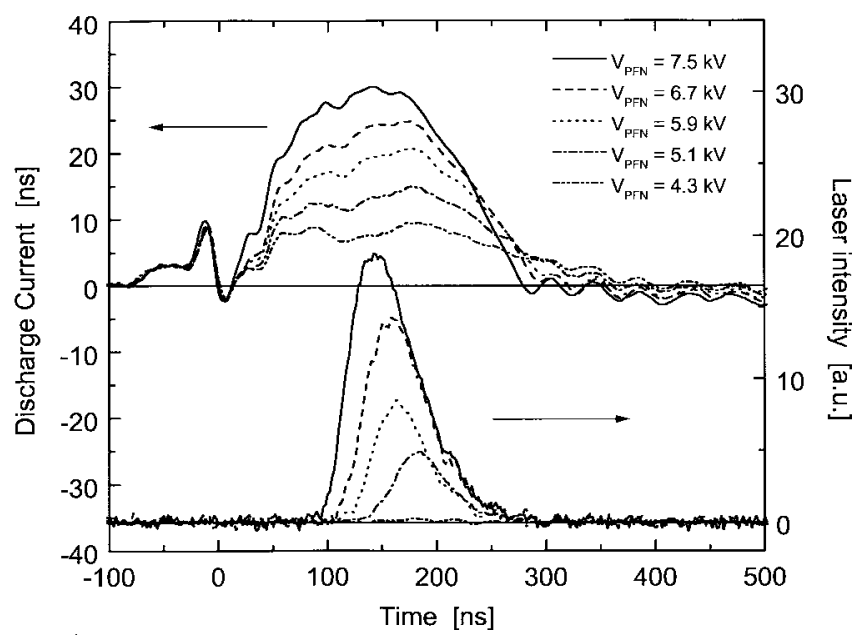

Fig. 11. Typical current and photodiode signals with different PFN voltage $V_{\mathrm{PFN}}=4.3-7.5 \mathrm{kV}$. Gas mixture: $5 \mathrm{bar}, \mathrm{F}_{2} / \mathrm{Ar} / \mathrm{He} / \mathrm{Ne}=1.0 /$ $50.0 / 19.1 /$ rest.

$\mathrm{V}_{\text {PFN }}>8 \mathrm{kV}$, the laser breaks down spontaneously during the charging of the PFN, before the preionization and the prepulse have been applied. Under these conditions, there is no homogeneous discharge and therefore no lasing.

In Fig. 11, the optical pulse is seen to start earlier in the discharge with increasing PFN-voltage. This indicates a higher gain, due to a higher pumping power. The peak of the optical signal coincides with the maximum in the current.

Theory predicts a faster discharge collapse due to a faster halogen depletion at an increased current density in the discharge [6], [7]. This has indeed been observed in other fluorine-containing lasers [4], [7].

In our setup, we do see a jump in the current signal which we attribute to the formation of arcs in the discharge. However, the effect does not increase with increasing currents and we do not observe a severe deterioration of the optical signal, although the increase in the pulselength wears off at higher charging voltages. This may be caused by the fact that our discharge electrodes are shaped in an Ernst-profile [13], which allows the discharge to become wider at higher voltages. This, in turn, decreases the current density while the total discharge current increases. Thus, the effects of an increased halogen depletion are attenuated. Additionally, an increased electron density causes a stronger electron quenching of the $\mathrm{ArF}^{*}$ molecules at higher voltages [20], [24]-[26], thus the laser performance increases less with an increasing current.

\section{CONCLUSION}

We have shown that a discharge pumped ArF excimer laser can be operated in the long pulse regime, yielding pulselengths of up to $120 \mathrm{~ns}$ at $4 \mathrm{~mJ} / \ell$. The generation of long pulses is possible due to the use of a setup with a profiled electrode and a very short current rise time at low operating voltages, as well as a gas composition with very low amounts of $F_{2}$ and Ar, which promote the long stability of the discharge.

The pulselength is shown to be primarily determined by discharge instabilities, which grow into filaments and arcs. The optical pulselength increases with decreasing partial pressures 
of the active ingredients, $\mathrm{F}_{2}$ and Ar. The laser performance is most sensitive to the fluorine content.

The optimum pulselength and optimum output power are found with different gas mixtures, because beneficial effects of the gain increase due to an increased formation efficiency of the $\mathrm{ArF}^{*}$ molecules are eventually surpassed by the degraded discharge quality. The optimum output energy at voltage matched conditions is $30 \mathrm{~mJ} / \ell$, at a pulselength of approximately $67 \mathrm{~ns}$, found with a gas mixture at 4.5 bar total pressure, consisting of $1.0 \mathrm{mbar} \mathrm{F}_{2}, 50.0 \mathrm{mbar} \mathrm{Ar}, 19.1 \mathrm{mbar} \mathrm{He}$ in the buffer gas Ne. Both the optical pulselength and the output energy are found to increase with increasing pumping power.

\section{REFERENCES}

[1] R. S. Taylor and K. E. Leopold, "Microsecond duration optical pulses from a UV-preionized XeCl laser," Appl. Phys. Lett., vol. 47, no. 2, pp. 81-83, 1985.

[2] R. S. Taylor and K. E. Leopold, "Ultralong optical-pulse corona preionized XeCl laser," J. Appl. Phys., vol. 65, no. 1, pp. 22-29, 1989.

[3] J.-M. Hueber, B. L. Fontaine, N. Bernard, B. M. Forestier, M. L. Sentis, and Ph. C. Delaporte, "Long pulse $\mathrm{KrCl}$ excimer laser at $222 \mathrm{~nm}$," Appl. Phys. Lett., vol. 61, no. 19, pp. 2269-2271, 1992.

[4] H. M. J. Bastiaens, S. J. M. Peeters, X. Renard, P. J. M. Peters, and W. J. Witteman, "Long pulse operation of an X-ray preionized molecular fluorine laser excited by a prepulse-main pulse system with a magnetic switch," Appl. Phys. Lett., vol. 72, no. 22, pp. 2791-2793, 1998.

[5] S. Bollanti, P. Di Lazarro, F. Flora, G. Giordano, T. Letardi, G. Schina, C. E. Zheng, L. Filippi, L. Palladino, A. Reale, G. Taglieri, D. Batani, A. Mauri, M. Belli, A. Scafati, L. Reale, P. Albertano, A. Grilli, A. Faenov, T. Pikuz, and R. Cotton, "Long-duration soft X-ray pulses by $\mathrm{XeCl}$ laser driven plasmas and applications," J. X-Ray Sci. Technol., vol. 5, pp. 261-277, 1995.

[6] J. Coutts and C. E. Webb, "Stability of transverse self sustained discharge-excited long-pulse XeCl lasers," J. Appl. Phys., vol. 59, no. 3, pp. 704-710, 1986.

[7] R. S. Taylor, "Preionization and discharge stability study of long optical pulse duration UV-preionized XeCl lasers," Appl. Phys. B, vol. 41, pp. $1-24,1986$.

[8] M. J. Kushner, "Microarcs as a termination mechanism of optical pulses in electric-discharge-excited KrF excimer lasers," IEEE Trans. Plasma Sci., vol. 19, pp. 387-399, Apr. 1991.

[9] F. A. van Goor, W. J. Witteman, J. C. M. Timmermans, J. van Spijker, and J. Couperus, "High average power $\mathrm{XeCl}$ laser with $\mathrm{X}$-ray preionization and spiker-sustainer excitation," in Proc. SPIE, High-Power Gas and Solid State Lasers, M. Bohrer, T. Letardi, D. Schuöcker, and H. Weber, Eds., 1994, vol. 2206, pp. 30-40.

[10] R. S. Taylor and K. E. Leopold, "Magnetic-spiker excitation of gasdischarge lasers," Appl. Phys. B, vol. 59, pp. 479-508, 1994.

[11] J. C. M. Timmermans, "Double discharge XeCl-laser," Ph.D. dissertation, Univ. of Twente, Enschede, The Netherlands, 1995.

[12] K. Midorikawa, M. Obara, and T. Fujioka, "X-ray preionization of raregas-halide lasers," IEEE J. Quantum Electron., vol. QE-20, pp. 198-205, Mar. 1984.

[13] G. J. Ernst, "Uniform-field electrodes with minimum width," Opt. Commun., vol. 49, no. 4, pp. 275-277, 1984

[14] S. J. Scott, "Development of a long life, $2 \mathrm{kHz}$ repetition rate $\mathrm{X}$-ray preionizer," Appl. Phys. B, vol. 56, pp. 201-208, 1993.

[15] F. A. van Goor, "Fast rise time X-ray pre-ionization source using a corona plasma cathode," J. Phys. D: Appl. Phys., vol. 26, pp. 404-409, 1993.

[16] J. W. Gerritsen, A. L. Keet, G. J. Ernst, and W. J. Witteman, "Highefficiency operation of a gas discharge $\mathrm{XeCl}$ laser using a magnetically induced resonant overshoot circuit," J. Appl. Phys., vol. 67, no. 7, pp. 3517-3519, 1990.

[17] R. Dreiskemper, G. Schröder, and W. Bötticher, "Light emission during cathode sheath formation in preionized high-pressure glow discharges," IEEE Trans. Plasma Sci., vol. 23, pp. 180-187, Apr. 1995.

[18] R. Dreiskemper and W. Bötticher, "Current filamentation of strongly preionized high pressure glow discharges in $\mathrm{Ne} / \mathrm{Xe} / \mathrm{HCl}$ mixtures," IEEE Trans. Plasma Sci., vol. 23, pp. 987-995, Dec. 1995.

[19] M. Makarov, J. Bonnet, and D. Pigache, "High efficiency dischargepumped XeCl laser," Appl. Phys. B, vol. 66, pp. 417-426, 1998.
[20] S. Nagai, H. Furuhashi, A. Kono, Y. Uchida, and T. Goto, "Measurement of temporal behavior of electron density in a discharge-pumped ArF excimer laser," IEEE J. Quantum Electron., vol. 34, pp. 942-948, Aug. 1998.

[21] L. Feenstra, O. B. Hoekstra, P. J. M. Peters, and W. J. Witteman, On the performance of an $\mathrm{ArF}$ and a $\mathrm{KrF}$ laser as a function of the preionization timing and the excitation mode. Appl. Phys. B. [On-line]. Available: DOI $10.1007 / \mathrm{s} 003409900119$

[22] P. J. Chantry, "Negative ion formation in gas lasers," in Appplied Atomic Collision Physics, Gas Lasers, E. W. McDaniel and W. L. Nighan, Eds. New York: Academic, vol. 3, pp. 35-70, 1982.

[23] F. A. van Goor, J. C. M. Timmermans, and W. J. Witteman, "The influence of charge-mode operation of a $\mathrm{XeCl}$ laser on the beam profile," Opt. Commun., vol. 124, pp. 56-62, 1996.

[24] M. Ohwa and M. Obara, "Theoretical evaluation of the buffergas effects for a self sustained discharge ArF laser," J. Appl. Phys., vol. 63, no. 5, pp. 1306-1312, 1988.

[25] A. M. Boichenko, V. I. Derzhiev, A. G. Zhidkov, and S. I. Yakovlenko, "Kinetic model of an ArF laser," Sov. J. Quantum Electron., vol. 22, no. 5, pp. 444-448, 1992.

[26] D. Lo, A.I. Shchedrin, and A. V. Ryabtsev, "The upper energy limit of a self sustained discharge-pumped ArF laser," J. Phys. D: Appl. Phys., vol. 29, pp. 43-49, 1996.

[27] A. V. Demyanov, L. Feenstra, P. J. M. Peters, A. P. Napartovich, and W. J. Witteman, "Kinetic modeling of a discharge pumped ArF excimer laser," J. Phys. D: Appl. Phys., submitted for publication.

[28] S. Nagai, M. Sakai, H. Furuhashi, A. Kono, T. Goto, and Y. Uchida, "Effects of $\mathrm{F}^{-}$ions and $\mathrm{F}_{2}$ molecules on the oscillation process of a discharge-pumped ArF excimer laser," IEEE J. Quantum Electron., vol. 34, pp. 40-46, Jan. 1998.

[29] H. Akashi, Y. Sakai, and H. Tagashira, "Modeling of a self sustained discharge-excited ArF excimer laser," J. Phys. D: Appl. Phys., vol. 27, pp. 1097-1106, 1994.

[30] M. Maeda, T. Nishitarumizu, and Y. Miyazoe, "Formation and quenching of excimers in low-pressure rare-gas/halogen mixtures by $e$-beam excitation," Jpn. J. Appl. Phys., vol. 18, no. 3, pp. 439-445, 1979.

[31] A. Garscadden, M. J. Kushner, and J. G. Eden, "Plasma physics issues in gas discharge laser development," IEEE Trans. Plasma Sci., vol. 19, pp. 1013-1031, Dec. 1991.

Louw Feenstra was born in Groningen, The Netherlands, on December 2, 1970. He received the M.Sc. degree in physics from the Leiden University, The Netherlands, in 1995 and is working toward the Ph.D. degree at the Quantum Electronics Group, Faculty of Applied Physics, University of Twente, The Netherlands.

His graduate research concerned the superconducting properties of variable pointcontacts in SQUIDS. His present research interests are the properties of long-pulse discharge pumped excimer lasers.

Hubertus M. J. Bastiaens was born in Rimburg, The Netherlands, on August 31, 1959. He received his diploma in technical physical engineering in 1981.

Since 1981, he has been with the Quantum Electronics Group, Faculty Of Applied Physics, University of Twente, The Netherlands, where has been involved in research on electron beam and discharge pumped gas lasers. $\mathrm{He}$ is presently engaged in the development of long-pulse, discharge pumped excimer lasers.

Peter J. Peters was born in Meerlo, The Netherlands, on November 5, 1945. He received the M.Sc. degree from the Catholic University in Nijmegen, The Netherlands. In 1981, he received the Ph.D. degree in laser physics at the University of Twente, The Netherlands.

He then joined the staff of the Quantum Electronics Group of the Faculty of Applied Physics of the University of Twente, The Netherlands, where he is now an associate professor. He has carried out research mainly in the field of gas lasers. His Ph.D. work on a pulsed TEA CO laser was followed by research work on different types of excimer lasers like $\mathrm{KrF}, \mathrm{ArF}, \mathrm{XeF}(\mathrm{C} \rightarrow$ $\mathrm{A}$ and $\mathrm{B} \rightarrow \mathrm{X}$ ) and on ionic excimers. Currently he is engaged in research on the VUV molecular $F_{2}$ laser and in the rare gas recombination lasers like the atomic Xe laser emitting in the near infrared. 
W. J. Witteman was born in Monster, The Netherlands, on December 12, 1933. He received the B.S. degree in mechanical engineering from the Technical University of Delft, The Netherlands, in 1958, and the Ph.D. degree in physics from the Technical University of Eindhoven, Eindhoven, The Netherlands, in 1963.

From 1958 to 1960 he was first as a Post-Doctoral Fellow and later as a Research Associate, at the Institute of Fluid Dynamics and Applied Mathematics, University of Maryland, College ParkMD, studying molecular relaxation phenomena by means of shock tube experiments. From 1961 until 1969, he was with Philips Research Laboratories, Eindhoven, the Netherlands, where he was engaged with high-pressure physics and technology until 1963 and after that he was doing research on water vapor lasers, sealed-off $\mathrm{CO}_{2}$ lasers and argon-ion lasers. Since 1969, he has been a professor at the University of Twente, Enschede, The Netherlands, where he is working on high-power pulsed laser systems. He is actively engaged in the field of $\mathrm{CO}_{2}$ lasers, mode-locking techniques, electron beam and discharge pulsed excimer lasers, both continuous and pulsed CO-lasers, electro-ionization lasers like $\mathrm{Ar}-\mathrm{Xe}$, waveguide lasers, and free-electron lasers of the Raman and Compton type. Since 1989, he also became managing director of Nederlands Centrum voor Laser Research (NCLR) B.V. which is a joint venture between the University of Twente and the industry. NCLR developes advanced laser systems for industrial applications like a 1-kW Eureka-excimer laser operating at $1 \mathrm{kHz}$. 